TP Periodica Polytechnica Civil Engineering

62(1), pp. 92-101, 2018

https://doi.org/10.3311/PPci.8698

Creative Commons Attribution (i)

RESEARCH ARTICLE

\section{New Formulations for Dynamic Behavior of Sand-Waste Tire Mixtures in a Small Range of Strain Amplitudes}

\author{
Ayse Edincliler ${ }^{1}$, Ali Firat Cabalar ${ }^{2 *}$, Abdulkadir Cevik², Haluk Isik ${ }^{2}$
}

Received 20 October 2015; Revised 13 January 2016; Accepted 20 April 2016

\begin{abstract}
This paper describes the results of a series of cyclic triaxial tests on sand - waste tire mixtures, and applications of genetic programming (GP) and stepwise regression (SR) for the prediction of damping ratio and shear modulus of the mixtures tested. In the tests, shear modulus, and damping ratio of the geomaterials were measured for a strain range of $0.0001 \%$ up to $0.04 \%$. The input variables in the developed GP and SR models are the waste tire content $(0 \%, 10 \%, 20 \%$, and $30 \%)$, waste tire type (tire crumbs or tire buffings), strain, and confining pressures $(40 \mathrm{kPa}, 100 \mathrm{kPa}$, and $200 \mathrm{kPa})$, and outputs are shear modulus and damping ratio. Test results show that the shear modulus and the damping ratio of the mixtures are strongly influenced by the waste tire inclusions. The performance of the proposed GP models $\left(R^{2}=0.95\right.$ for shear modulus, and $R^{2}=0.94$ for damping ratio) are observed to be more accurate than that of the SR models $\left(R^{2}=0.87\right.$ for shear modulus, and $R^{2}=0.91$ for damping ratio).
\end{abstract}

\section{Keywords}

sand, waste tire, cyclic triaxial testing, stepwise regression, genetic programming

\footnotetext{
${ }^{1}$ Bogazici University, Kandilli Observatory and Earthquake Research Institute, Istanbul, Turkey

${ }^{2}$ University of Gaziantep, Department of Civil Engineering, Gaziantep, Turkey

* Corresponding author: cabalar@gantep.edu.tr
}

\section{Introduction}

Today waste tires have become a growing concern as in the past, and each year the world generates more waste tires. This could mainly be attributed to increase in population and therefore the demands of the world for more vehicles to be produced, which means more waste material to be accumulated after they reach their end of life. As this material is manufactured from petroleum products, it can't be dissolved or recycled in nature; therefore a necessity arises to dispose of these materials. Current disposal methods include burning stockpiles of waste tires, which has obvious health and environmental risks. An alternative method would be to recycle these materials and therefore contribute to a healthy environment. Many developed and also developing countries are working on putting out laws, ordinances or state wise legislations regarding the use or recycling of waste tires that would allow them to be used in a civil engineering context. ASTM International already has such standards as to the use of scrap tires in civil engineering applications. They have defined and classified scrap tires according to their sizes, processing, and shape or type (whether it is a whole tire, a slit tire, shredded tire, chipped tire, ground rubber or crumb rubber). Waste tires have been in the field of interest of many civil engineers. Although there is much research that needs to be done on the topic, there are current applications involving the recycling of said materials. These discarded materials are sometimes used in reinforcement of weak soil, slope stabilization or as a backfill in retaining structures [1-8]. Soil mixed with waste tires have been shown to possess a higher compressibility, low void ratio, high friction angle, and high attenuation [9-15]. Finding the damping ratio and shear modulus of waste tire mixtures will be the scope of interest of this paper, and in accordance with that, behavior of sand-waste tire mixtures will be studied and two different approaches, namely SR and GP, for modeling the mentioned properties of waste tires will be presented.

In previous research in the literature regarding waste tires, static and dynamic properties of soil and discarded tire mixtures had been studied. There have been many studies on the compressibility properties of waste tire shreds [1, 16-17]. In general, 
the results of these studies concluded that when the tire scraps had an initially loosely packed structure, they have exhibited better compressibility than that of other tire shreds which were slightly denser. Further investigations were done in order to determine the shear strength parameters of waste tires, which included direct shear tests and monotonically loaded triaxial tests [14, 18-21]. The researchers tried to examine behavior of the waste tire and sand mixtures as they increased the amount of waste tires in the mixtures. The common reports of these investigations were that the shear strength of sand and waste tire mixtures had increased only up to a certain point where any more raise in the ratio of tires would degrade the quality of the mixtures. However, the shear strength parameters were not only bound to the ratio of waste tires. Several other factors, namely; normal stress, unit weight of the sand matrix, aspect ratio, compaction degree and also processing techniques were shown to greatly affect the parameters of the sand mixtures [22]. Edinciler et al. [22] pointed out that out of the mentioned factors, it was processing techniques of discarded tires, which proved to be the most effective in influencing the shear strength parameters. Optimum soil behavior and compaction characteristics was achieved when the waste tire ratio in the mixtures allowed to be under $35-40 \%$; it was then observed that the mixtures had a sand-like response, they had high shear strengths, and dilatant behavior [14]. The researches done until very recently on the topic included investigation of basic soil properties such as compaction, compressibility, permeability, shear strength, modulus of elasticity, and Poisson's ratio. These studies, however, did not provide a comprehensive overview of the dynamic properties of soils in relation with the waste tire ratio [11, 25-28]. Owing to their elastic properties, mixtures composed of sand and waste tires could prove a useful element in energy dissipation, and therefore in seismic energy absorption in underground tunnels [29-31]. Shear strength of scrap tire and soil mixtures is significantly higher than that of regular soil. In addition to this, these mixtures also have an excellent energy dissipation capacity [2]. Edincliler et al. [32] have increased tire shred weight by $10 \%$ in a sand and scrap tire mixture in their studies, and it was shown that an increase by this amount caused the mixture to have a lower shear modulus but also improved its damping property significantly [32]. Kim and Santamarina [26] increased the waste tire ratio in the mixture, and they showed that the mixture followed a certain pattern in which its shear wave velocity gradually increased and then started to decrease after the waste tire ratio hit 20\%. A similar behavior, this time regarding the stiffness and damping ratio, was observed by Pamukcu and Akbulut [15]. Feng and Sutter [11], and Anastasiadis et al. [33] reported that when the waste tire content was increased in a given waste tire and sand mixture, this resulted in a decrease of stiffness and an increase of damping ratio of the mixture. Anastasiadis et al. [33] also showed that these changes in the properties of the mixture occurred in a close-to-linear fashion when the waste tire ratio allowed to be changed in the range of medium to high strain level. Later studies done on the waste tire mixtures regarding the influence of confinement time have suggested analytical relationships between shear modulus and damping ratio of the mixtures at various strain levels $[34,35]$. However, it should be noted that these mentioned studies were conducted on mixtures that were composed of fine to medium grained uniform sands.

The studies on the dynamic characteristics of soil - waste tire mixtures can be developed even further, and there is potential in areas such as earthquake analysis of the fills for slopes, embankments and retaining walls. In this study however, we were concerned with shear modulus and damping ratio of the mixtures, and these characteristics were computed using a cyclic testing instrument. We first separated the samples into mixtures with diverse percentages of waste tires and sand. The maximum value of shear modulus and the minimum value of damping ratio were represented with the percentage of waste tires. In this paper we provided the experimental results of the relevant tests on the sand - waste tire mixtures, and two different approaches in approximating the damping ratio and shear modulus were discussed, namely Stepwise Regression (SR) and Genetic Programming (GP). We compared our results with the previous studies on SR and GP [36, 40], and found out that our estimations fell in line with earlier studies. An advantage of our approach is that we can also develop mixture rules that assist us in estimating the variation of dynamic properties in relation to the ratio of waste tires to soil. As examined herein, the variation of maximum shear modulus in relation to the percentage of waste tires, type of waste tires, amount of confining pressure, and strain level, provides insight into how mixture rules could be established for particulate mechanics of earth structures that include non-earth materials.

\section{Experimental Study}

In the experiments that were conducted during the study, our goal was to evaluate the dynamic properties of sand along with the dynamic properties of several sand and waste tire mixtures, which were also tested using a triaxial test equipment. Waste tires that are used in the experiment are recycled tires in the forms of tire crumbs (TC) and tire buffings (TB), which were included in $10 \%, 20 \%$ and $30 \%$ by weight in the mixtures.

A type sand that is known as "Silivri sand" was used in our experimental setup. This particular type of sand is commonly used in highway embankments in Turkey, and is found around Silivri, Istanbul, hence the name. A sample of sand was collected from the location and sieve analysis was performed in compliance with the ASTM code D422. After observing the results, the coefficient of uniformity $(\mathrm{Cu})$ and the coefficient of curvature $(\mathrm{Cc})$ were determined to be 2.4 and 1.35 , respectively. Using the Unified Soil Classification System (USCS), these values then lead to the classification of the soil as uniformly graded sand, which is denoted by the symbol "SP". 
Tire crumb, which is also called a crumb rubber is basically a rubber material generally derived from recycled vehicle tires. Tire buffing is a similar material, which is a waste product of buffering process of tires. They come in fiber shapes and are very lightweight as tire crumbs also are. These materials were purchased from companies in Istanbul, Turkey.

Particles of the tire buffings were of differing sizes; therefore we observed the gradation of the material according to ASTM D4767-04, after which we acquired a sample with particle sizes at the desired lengths. An aspect ratio of 1/5 for the tire buffings was preferred to use in the experiments. Pictures of tire buffings and tire crumbs are shown in Figure 1.

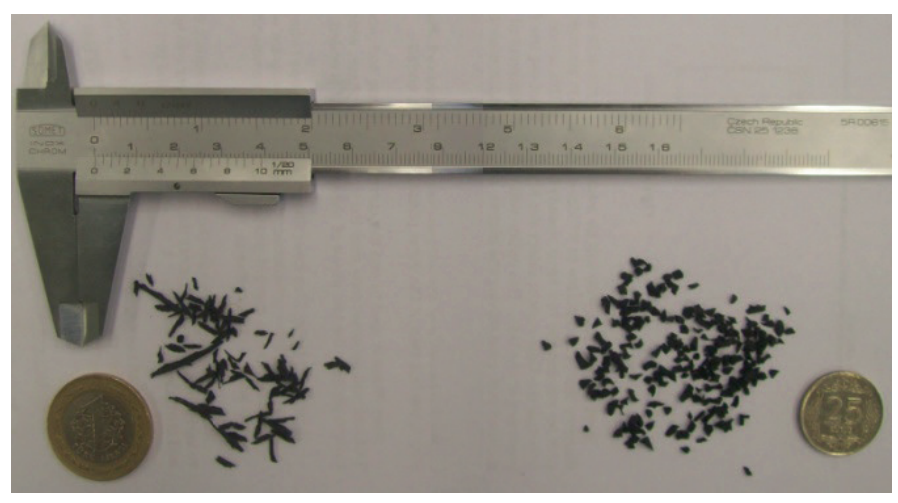

Fig. 1 Tire buffings and tire crumbs samples used in the experimental studies

Another important parameter of these waste materials is relative density in terms of geotechnical engineering. We calculated the relative densities of the specimens of sand, tire crumb and tire buffings with triaxial tests. These triaxial tests conforms to the standard codes of ASTM D 4253-83 and ASTM D4254-83 using a standard compaction mold of $864 \mathrm{~cm}^{3}$ in volume and a standard compaction hammer. In the aforementioned ASTM codes, calculating relative density comprises of two steps where for a given material, a minimum density for its loose state and a maximum density for its most compacted state is measured. In our case, the minimum densities were determined after the mold was filled with the loose material. The maximum densities of the materials were determined in a process whereby the mold is filled in 5 layers, and each layer is formed by hammering the material with fifteen blows. The calculated results of relative densities are shown in Table 1.

Table 1 Density and relative density values of samples

\begin{tabular}{lcccc}
\hline Sample & $\begin{array}{c}\text { Minimum } \\
\left(\mathrm{kN} / \mathrm{m}^{3}\right)\end{array}$ & $\begin{array}{c}\text { Maximum } \\
\left(\mathrm{kN} / \mathrm{m}^{3}\right)\end{array}$ & $\begin{array}{c}\gamma \\
\left(\mathrm{kN} / \mathrm{m}^{3}\right)\end{array}$ & $\begin{array}{c}\text { Dr } \\
(\%)\end{array}$ \\
\hline \%100 Sand-S & 14.40 & 15.70 & 14.90 & 0.38 \\
\% 10 Crumbs (TC10) & 12 & 13.80 & 12.60 & 0.37 \\
\% 20 Crumbs (TC20) & 10.60 & 12.40 & 11.20 & 0.37 \\
\% 30 Crumbs (TC30) & 9.90 & 11.30 & 10.30 & 0.34 \\
\% 10 Buffings (TB10) & 11.10 & 13.30 & 11.80 & 0.35 \\
\% 20 Buffings (TB20) & 8.90 & 11.00 & 9.50 & 0.31 \\
\% 30 Buffings (TB30) & 7.80 & 9.70 & 8.50 & 0.44 \\
\hline
\end{tabular}

All the experiments were carefully conducted in stresscontrolled environments using a standard cyclic triaxial testing equipment of ASTM D3999. This equipment allows testing of specimens that are 50 or $100 \mathrm{~mm}$ in diameter with a height twice the size of its diameter. In order to have uniform mixtures of sand and waste tires (of either TB or TC) we prepared the mixtures by dry mixing sand with chosen percentages of TB and TC which were $0 \%, 10 \%$ and $30 \%$ by weight. After this step, we formed the specimens in dimensions of $100 \mathrm{~mm} \times 200$ $\mathrm{mm}$ inside a metal mold and laid each mold separately on top of the pedestal of the triaxial test apparatus. For determining the maximum densities, each of the specimens was prepared in 5 layers. For measuring the minimum densities, the specimens were prepared in 3 layers of equal dry mass without allowing any disturbance in each layer so as to acquire a lowest density possible in laboratory conditions. The experiments resulted in approximately same relative density measurements for all of the specimens, which are shown in Table 1.

It is worthwhile to mention the fact that the experiments were conducted with a certain type sand and with sand - waste tire mixtures in which waste tire content varies only up to $30 \%$ by weight. There is a valid reason behind this decision and it is that as waste tire content gets higher the mixture quickly acquires rubber-like characteristics, which we did not intend to have. It has been shown in earlier studies that for waste tire content above $60 \%$ by weight, the sand mixtures exhibit a rubber-like behavior. When the mixture reaches as high a content of waste tires as $60 \%$, it was observed that rubber-to-rubber interfaces would emerge and that the waste tires inside the mixture would be more in control of the overall static and dynamic response of the mixtures [26].

\section{Analysis of Test Results}

The test results were analyzed with regards to the loaddeformation response, the shear modulus and the damping ratio of the mixtures. The behavior of waste tires with varying contents were observed and corresponding strain shear modulus (G) and damping ratio (D) values were recorded, which are shown in Figure 2 through Figure 5. The main effect observed was that regardless of confining pressure of the mixtures, $G$ and $\mathrm{D}$ of waste tire crumbs increases. We measured confining pressure values of G and D to be $40 \mathrm{kPa}, 100 \mathrm{kPa}$, and $200 \mathrm{kPa}$. Figure 2 and 3 show how the small strain shear modulus and damping ratio of the mixtures that are tested under $100 \mathrm{kPa}$ is affected by varying contents of tire buffings and waste tires. 


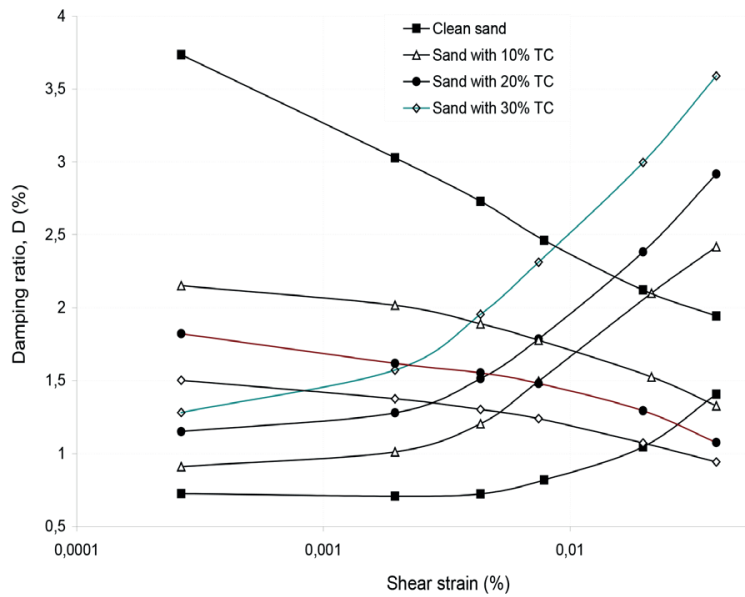

Fig. 2 Sand with tire crumbs at various contents under $100 \mathrm{kPa}$ confining pressure

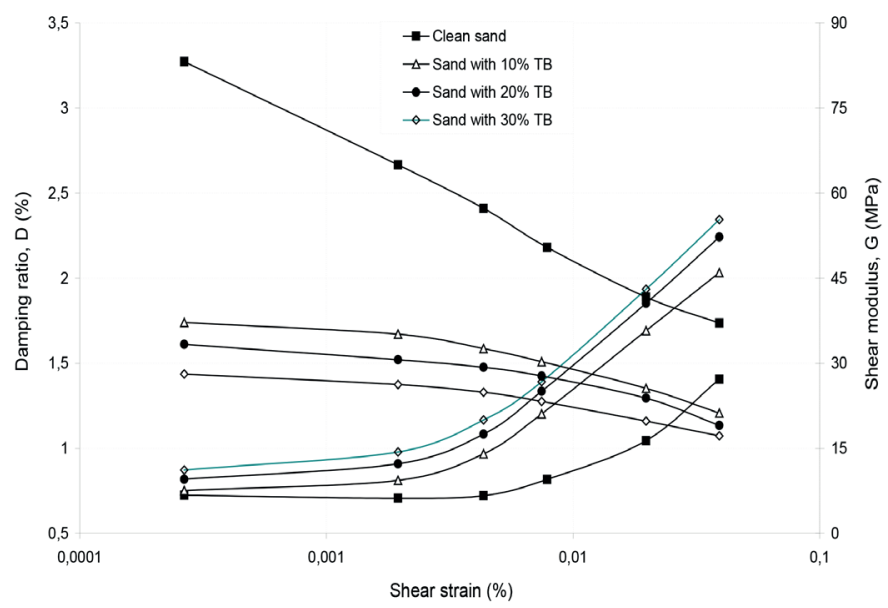

Fig. 3 Sand with tire buffings at various contents under $100 \mathrm{kPa}$ confining pressure

The comparative analysis shown here evidently demonstrates that as the waste material content increases, the stressstrain response of the mixture to cyclic loading gets smoother. It is shown that as the proportion of waste materials introduced in sand gets higher, we have lower shear modulus values. It is also demonstrated that $\mathrm{G}$ increases as $\mathrm{D}$ also increases, for a given strain level. The mixtures with less waste tire ratios were observed to display a more linear response when they were at relatively small strain levels. Conversely, mixtures with higher waste material ratios were observed to possess a relatively elastic response. As Feng and Sutter [11] also reported in their investigations, damping response in a given waste tire - sand mixture may be resulting from (i) the friction between each particle or (ii) the deformation of each particle. Particles of sand are known to be stiff, which explains why they dissipate small amounts of energy during deformation. On the other hand, owing to their highly elastic nature particles of each waste tire are known to consume high amounts of energy. The change in $\mathrm{G}$ and $\mathrm{D}$ values under the influence of confining pressure for a specimen of $20 \%$ waste tire ratio is shown in Figure 4 and Figure 5. It can be seen from the figures that as the introduced confining pressures increase, the mixtures have a tendency to display higher $\mathrm{G}$ values and lower $\mathrm{D}$ values.

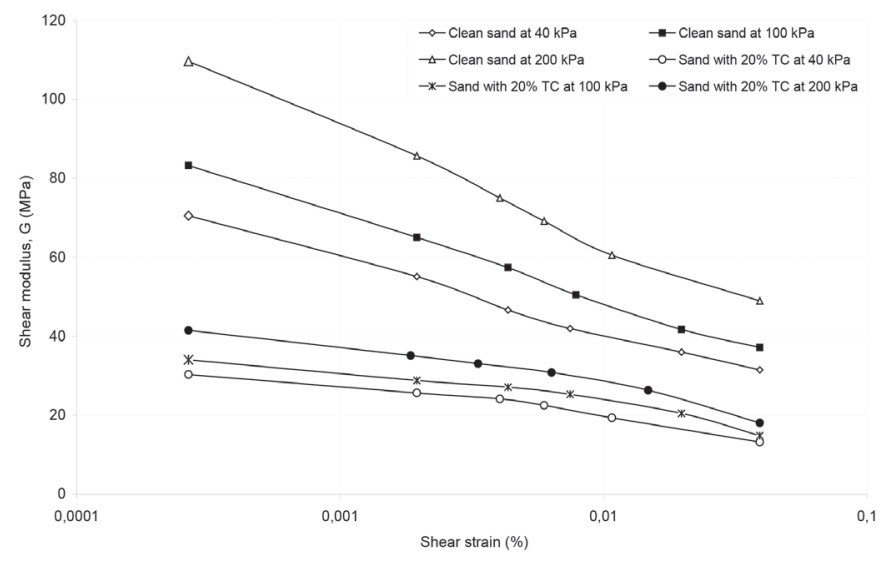

Fig. 4 Effect of confining pressure on shear modulus of the sand with $20 \%$ TC

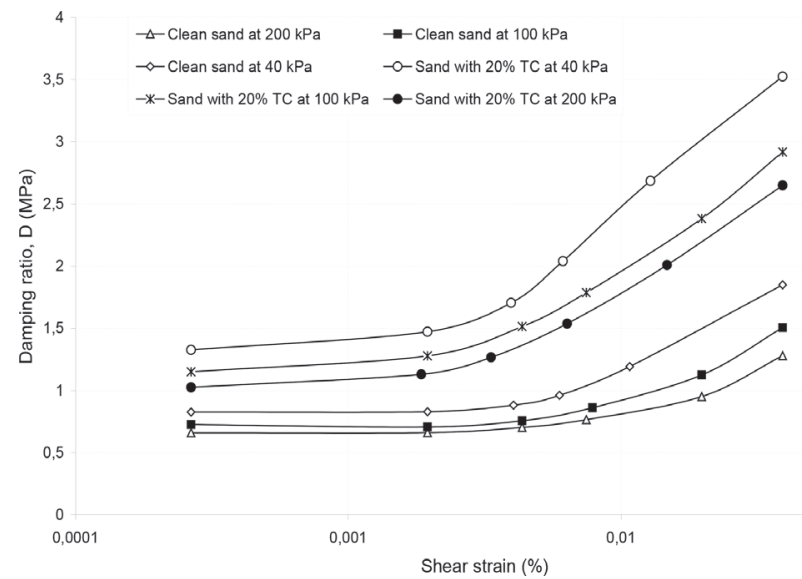

Fig. 5 Effect of confining pressure on damping ratio of the sand with $20 \%$ TC

\section{Stepwise Regression}

Dealing with large numbers of independent variables as we have in the experiments, requires the best combination of such variables to be specified in order to determine the dependent variable. Stepwise Regression (SR) a semi-automated process, which helps to determine the best subset of models [41]. The process involves the variables are either being added together or deleted which have the greatest effect on the residual sum of squares. Subset variables are selected using one of three ways, which can be a forward selection, or a backward elimination, or a combination of both of them. In the first method, the procedure starts with no variables involved, they are added one at a time according to a given criterion. The second method however involves a procedure that starts out with all the candidate variables, goes on to eliminate each of the variables until no further progress is possible and there is only one variable left [42]. In the procedure, which utilizes both methods, the variables at each step are tested whether to be included or not. Each step is significant in this procedure in that, they may be reevaluated according to the previous variables. The direction of selection may change to backward when a partial sum of squares value for a variable do not meet a certain minimum. From that point on, the variables are then evaluated as in the backward elimination method until they meet the minimum 
requirement. In stepwise regression, when the forward direction method is chosen it requires more computing power, but it also has a certain advantage that it can evaluate potential subsets even before each subset size is determined. It may be concluded that stepwise regression analysis has a great advantage of being able to provide the most suitable subsets for a given data while not guaranteeing every time that the subsets will be the best ones. The procedure uses forward elimination and backward elimination criteria interchangeably to choose the subsets and end the selection process. If there are no more variables left that requires staying in the model, and no outside variable is to be entered then the selection process is said to be completed [42].

The aim of this paper is to develop empirical formulas that determine shear modulus $(\mathrm{G})$, and damping ratio (D) of waste tire crumbs/buffings and sand mixtures by utilizing SR techniques on the data obtained by experiments.

\section{Genetic Programming}

Genetic programming (GP) is an artificial intelligence methodology inspired by biological evolution and natural selection that aims to solve complex engineering problems. A genetic algorithm (GA) is the procedure of calculations involved in the genetic programming. Using GP, it is possible to let members of a certain group of people evolve under previously determined rules and maximize their fitness properties. A fitness property for example, may be a one that minimizes the cost function. GP first appeared in use in 1954 by Nils Aall Barricelli, who used the method to simulate biological evolution of species. The method was further improved by Holland [43], and one of his $\mathrm{PhD}$ students, Goldberg used it to solve a sophisticated engineering problem related with the control of a gas pipeline as documented in 1971 [45]. By the 1970's genetic programming had already found its way as a popular method of optimization. The fitness in a GA is a measure that determines how well an individual is adapted to the environment and how well he/she performed to solve a given problem. In other words, it is a property whereby an optimum solution is presented for the problem, and each solution of a problem is represented by an individual in the genetic algorithm. Therefore, in order to have an algorithm that works as expected and that can solve complex problems, individuals who are best fit needs to be selected, because fitness is the most important parameter in a GA [41]. Koza proposed genetic programming as an extension to GA's [46]. According to Koza, GP has the potential to solve any programs independent of a domain by allowing computer programs to evolve as in Darwinian theory of natural selection and survival of the fittest. Therefore, genetic programming can be thought of as analogous to evolution where every phenomenon in evolution also takes place, including sexual recombination and mutation. The steps that GP follows in order to solve problems using computers is as follows (Figure 6):

(i) Generate an initial population of random compositions of the functions and terminals of the problem (computer programs).

(ii) Execute each program in the population and assign it a fitness value according to how well it solves the problem.

(iii) Create a new population of computer programs.

(a) copy the best existing programs (reproduction)

(b) create new computer programs by mutation.

(c) create new computer programs by crossover (sexual reproduction).

(d) select an architecture-altering operation from the programs stored so far.

(iv) The best computer program that appeared in any generation, the best-so-far solution, is designated as the result of genetic programming [46].

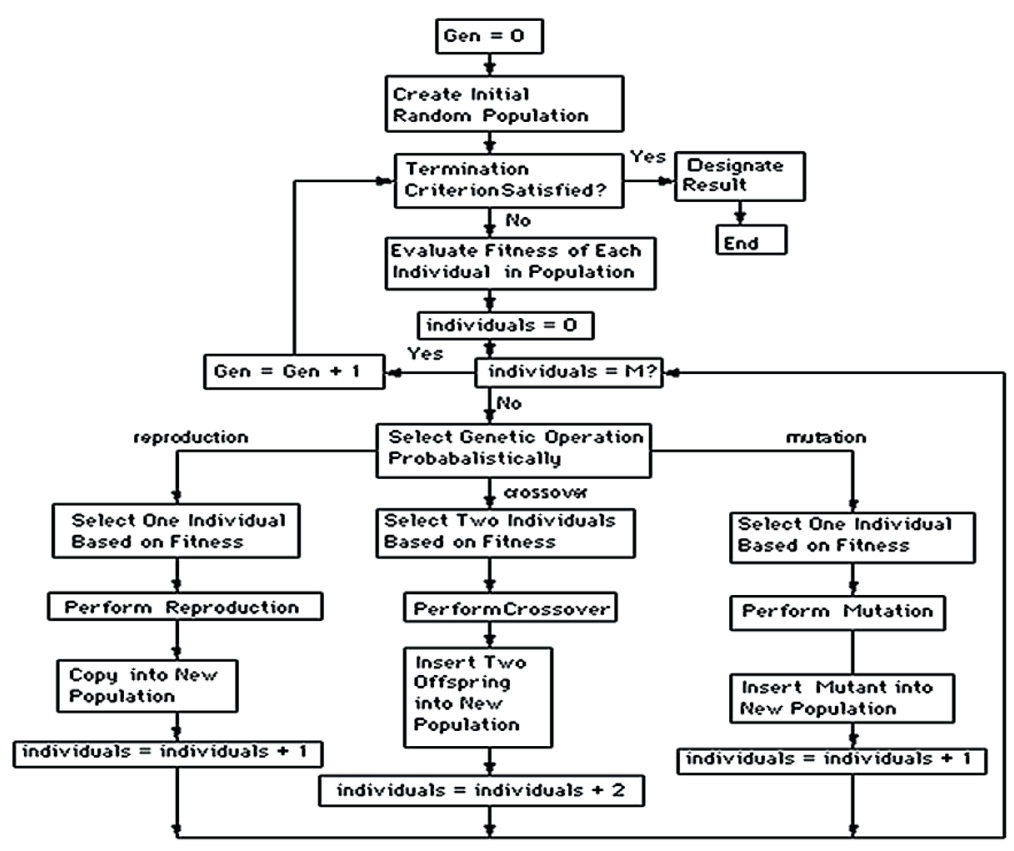

Fig. 6 Genetic Programming Flowchart (Koza, 1992) 


\subsection{Brief overview of GEP}

Gene expression programming (GEP) is a computer algorithm that creates other computer programs or models. It is based on GP that simulates evolution of computer programs of given sizes and shapes that can be encoded in linear chromosomes having fixed lengths. The chromosomes incorporated by the program have multiple genes with each gene having the ability to encode other computer programs. Linear chromosomes have the structural organization akin to normal chromosomes and they can perform operations on genes like recombination, transposition and mutation. One of the stronger points of GEP over GP is that its genetic operators work at the chromosome level and the creation process to achieve a genetic diversity is much simplified. Another powerful feature is its ability to simulate an evolution of programs consisting with many subprograms and that are more complex that those created by GP. GEP is a much-improved version of GP whereby users can create programs that behave much like living organisms, and it is said to have a computing power that is 100-10,000 times powerful than that of GP system [46-49]. In this study, we used the computer software called GeneXTools (www.gepsoft.com), which is developed by Candida Ferreira.

The main differentiating factor between GA, GP and GEP lies in the fact at how the individuals are selected. It was stated that in GA the individuals are only linear strings having constant lengths as in chromosomes; whereas in GP, the individuals are not linear and they can have different sizes and shapes as in trees; and lastly in GEP which is the closest method of simulating a living organism, the individuals are linear strings of the same length just like in GA, but they later transform into nonlinear entities each having different shapes and sizes. It can be stated that there are two fundamental parameters involved in GEP: chromosomes and expression trees (ETs). In GEP, the information first gets decoded from chromosomes into expression trees, and this process is known as translation. The genetic code of GEP is a basic one-to-one relationship between symbols of the genome and the functions they represent, which are called terminals. The rules that are used in the program specify the spatial organization of the functions and terminals in the ETs and the type of interaction between sub-ETs [46-49].

There are two languages that are used in GEP, namely the language of the genes and the language of ETs. Given a certain gene sequence, GEP is able to derive the exact phenotype, and vice versa. This process is called Karva language and it is a great advantage of using GEP over other systems. For example, consider the following algebraic expression.

$$
\left(d 4^{*} \sqrt{\left(d 3-d 0+d 1^{*} d 4\right)}-d 4\right) .
$$

The diagram in Figure 7 represents the expression, which corresponds to an expression tree.

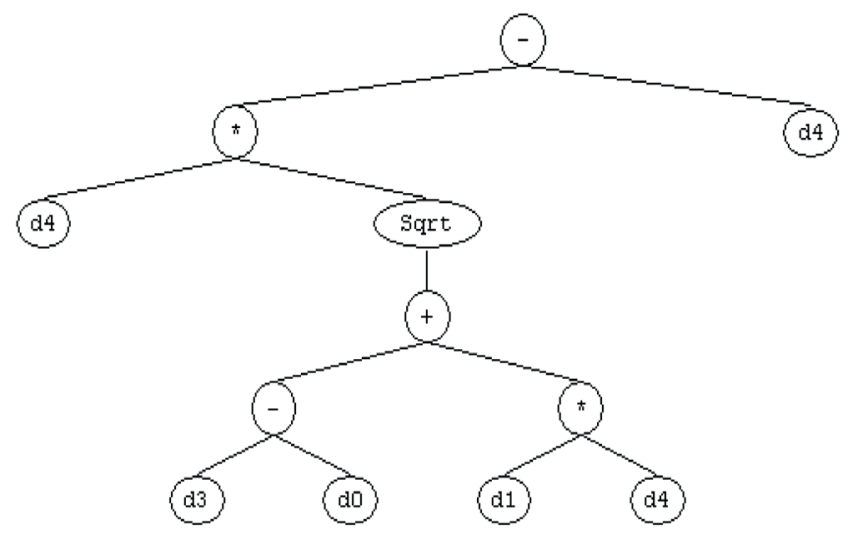

Fig. 7 Expression tree (ET)

\section{Numerical Applications}

Nonlinear response of waste tire - sand mixtures were experimentally observed after which numerical simulations were performed with the obtained data. In order to create a numerical model, we first established two systems, and then we modeled waste tire - sand mixtures.

Using Stepwise Regression and Genetic Programming techniques, the study aims to propose formulations that can be used to calculate damping ratio and shear modulus properties of sand - waste tire mixtures. The details regarding the experiments conducted for the investigation and an outline of the systems used for the numerical analysis are given in previous sections. Using the Stepwise Regression, shear modulus $(G)$ and damping ratio $(D)$ properties were modeled as a function of confining pressure $(\sigma, \mathrm{kPa})$, strain $(\varepsilon, \%)$, waste tires type $\left(T_{w t}\right)$, and waste tire content $\left(C_{w t}\right)$, and the following equations were obtained;

$$
\begin{gathered}
G=60.49-6.40 \cdot \sqrt{C_{w t}}-755.44 \cdot \sqrt{\frac{\varepsilon}{\sigma}}+8.9 \cdot 10^{-6} \cdot \frac{\sigma^{2}}{T_{w t} \cdot \sqrt{\varepsilon}} \\
D=0.88+\frac{11.62 \cdot T_{w t} \cdot \sqrt{C_{w t} \cdot \varepsilon}}{\sqrt{\sigma}}
\end{gathered}
$$

Using the Genetic Programming, the database was divided into two parts consisting of a training set (80\%) and a testing set $(20 \%)$ so as to prevent over-fitting and to obtain a generalization. The patterns used in both sets were randomly selected. We created the formulas based on training sets. Testing sets were there to test the parameters against, in order to measure their reliability and the scope they are effective in. After all the parameters are put into the equations we obtained the final form for $\mathrm{G}$ and $\mathrm{D}$ as follows;

$$
\begin{gathered}
G=16.3+\frac{257+\sigma-257 \cdot \varepsilon \cdot T_{w t} \cdot C_{w t}}{5.34+C_{w t}+562 \cdot \varepsilon} \\
D=0.73+\log \left(18.8 \cdot \varepsilon+9.44 \cdot \varepsilon \cdot T_{w t} \cdot C_{w t}+\sqrt{T_{w t}}\right. \\
\left.-0.0354 \cdot \sigma \cdot \varepsilon \cdot T_{w t} \cdot C_{w t}\right)
\end{gathered}
$$


$\sigma=$ Confining pressure $(\mathrm{kPa})$

$\varepsilon=$ Strain $(\%)$

$T_{w t}=$ Waste tire type ( 1 for tire buffings, 2 for tire crumbs)

$C_{w t}=$ Waste tire content

The parameters related with the training sets of our GP models are given in Table 2. Table 3 presents the statistical parameters used in training and testing sets and also gives the calculation results of the models. Figures 8 through 11 show shear modulus and damping ratio values calculated using GP vs. test results. For a comparison of SR/GP and test results, some typical diagrams are presented in Figures 12 through 15. Figures 12 and 13 shows a comparison of the proposed SR and GP models for the soil mixtures of $10 \%$ waste tire content with the test results. As it is seen in the figures, the proposed GP and SR models gave reasonable shear modulus and damping ratio values for the mixtures of $10 \%$ waste tire content that are tested under differing confined pressures. Figures 14 and 15 show a comparison of GP/SR models with the test results of waste tires. The diagrams in these figures also indicate a close relationship with the test results. It's worth mentioning however, in order to obtain a conclusion regarding the accuracy of the models, the database should be considered as a whole. In light of this information, as it is seen in Figures 8 through 11, the GP model is found to be more accurate in comparison to the $\mathrm{SR}$ model in terms of the correlation coefficient $\left(\mathrm{R}^{2}\right)$.

Table 2 Parameters of the GEP models

\begin{tabular}{lcc}
\hline P1 & Function Set & $+,-,{ }^{*}, /, \sqrt{ }, \mathrm{e}^{\mathrm{x}}, \ln (\mathrm{x})$, Power \\
\hline P2 & Chromosomes & $30-3000$ \\
P3 & Head Size: & $6,8,10,15,20$ \\
P4 & Number of Genes: & 2 \\
P5 & Linking Function: & Addition, Multiplication \\
& Fitness Function Error Type: & MAE (Mean Absolute Error), \\
P6 & Custom Fitness Fuction \\
& Mutation Rate: & 0,044 \\
P7 & Inversion Rate: & 0,1 \\
P9 & One-Point Recombination Rate: & 0,3 \\
P10 & Two-Point Recombination Rate: & 0,3 \\
P11 & Gene Recombination Rate: & 0,1 \\
P12 & Gene Transposition Rate: & 0,1 \\
\hline
\end{tabular}

Table 3 Statistical Parameters of learning and training sets and overall

\begin{tabular}{ccccc}
\multicolumn{5}{c}{ results of GP models } \\
\hline \multirow{2}{*}{$\begin{array}{c}\text { Damping ratio } \\
\text { (D) }\end{array}$} & Training Set & 0,989 & 0.116 & 0.929 \\
& Testing Set & 0.999 & 0.120 & 0.932 \\
& Overall & 0.998 & 0.119 & 0.933 \\
Shear modulus & Training Set & 1.007 & 0.106 & 0.956 \\
(G) & Testing Set & 0.988 & 0.118 & 0.944 \\
& Overall & 0.994 & 0.118 & 0.944 \\
\hline
\end{tabular}

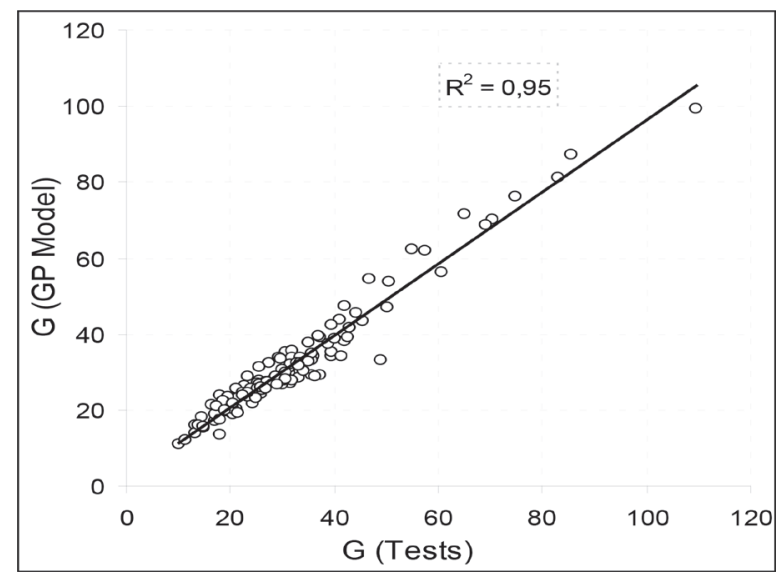

Fig. 8 GP vs. Test results for shear modulus

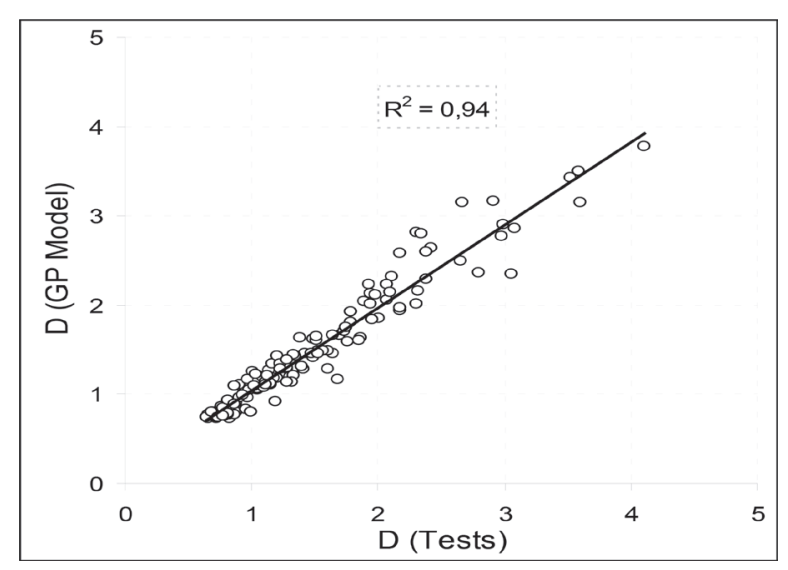

Fig. 9 GP vs. Test results for damping ratio

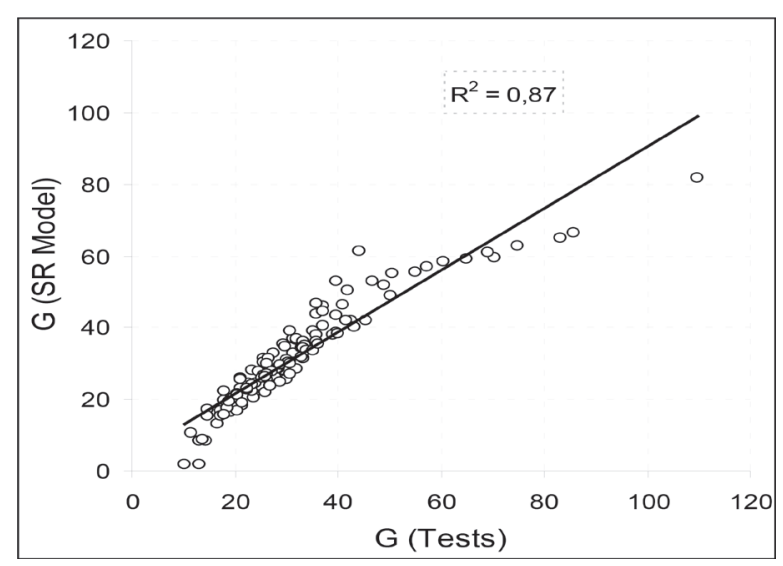

Fig. 10 SR vs. Test results for shear modulus

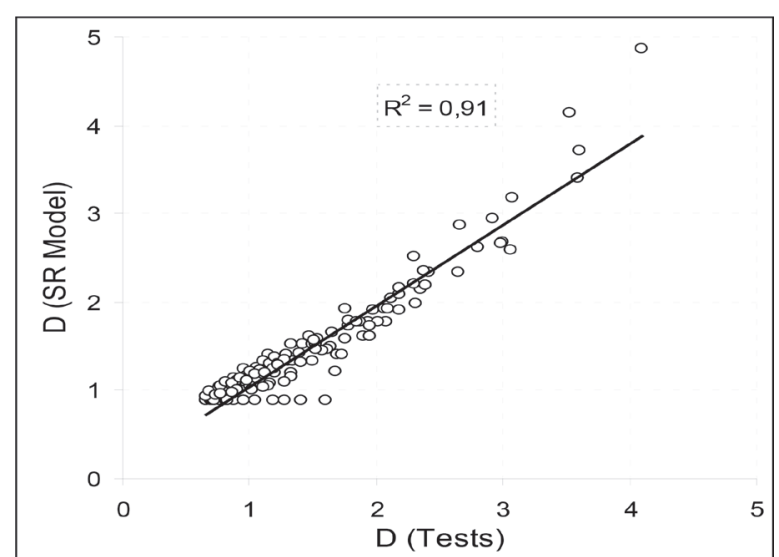

Fig. 11 SR vs. Test results for damping ratio 


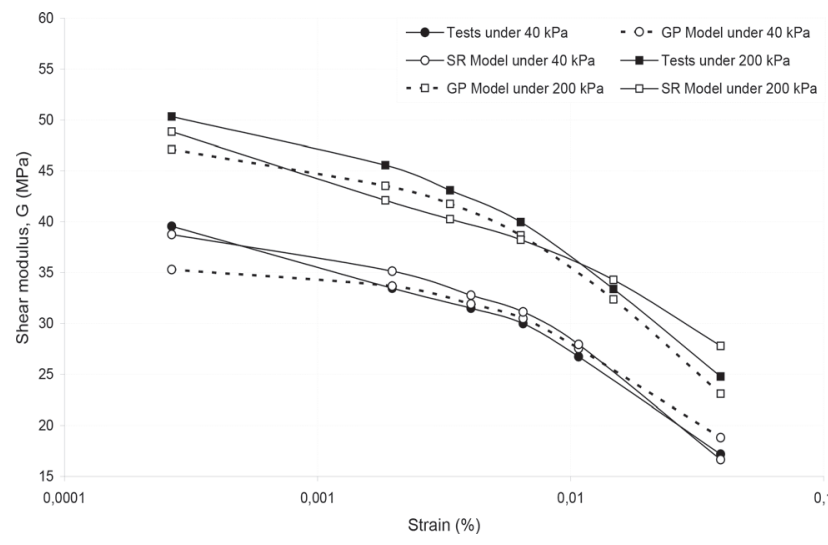

Fig. 12 Comparison for the sand with $10 \%$ tire crumbs

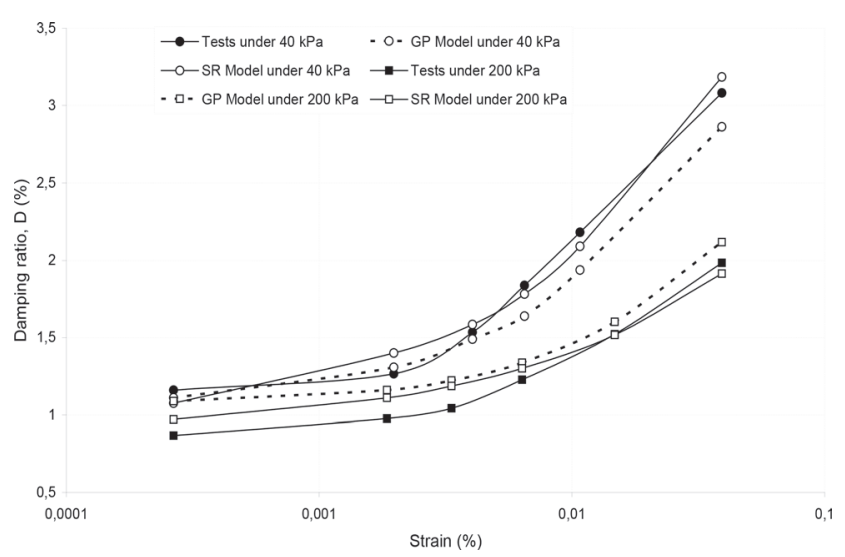

Fig. 13 Comparison for the sand with $10 \%$ tire crumbs

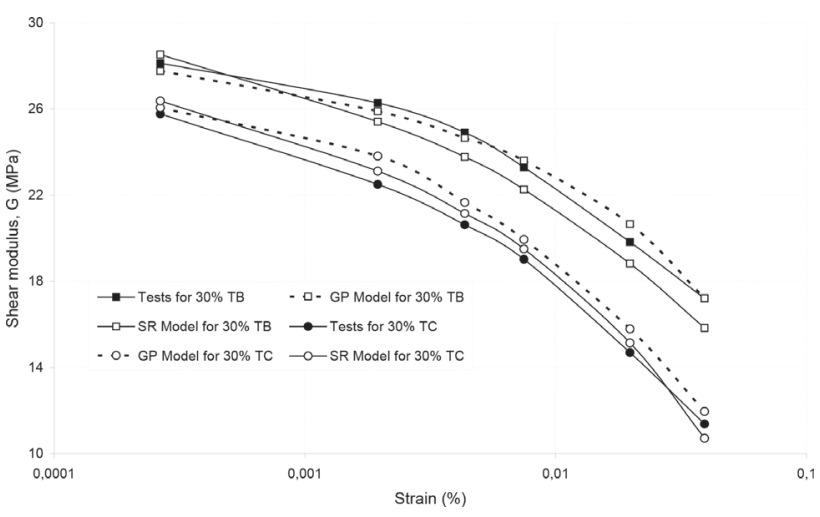

Fig. 14 Comparison for the sand with $30 \% \mathrm{TC} / \mathrm{TB}$ under $100 \mathrm{kPa}$ confining

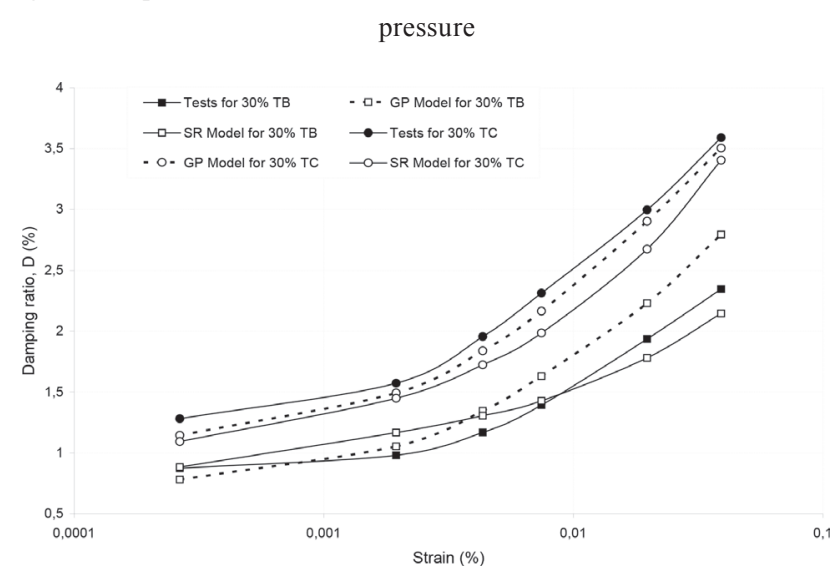

Fig. 15 Comparison for the sand with $30 \% \mathrm{TC} / \mathrm{TB}$ under $100 \mathrm{kPa}$ confining pressure

\section{Conclusions}

The paper presents cyclic triaxial test results for sand mixed with waste tire crumbs and buffings. Shear modulus and damping ratio at small strain levels are presented against shear strain, and two different modeling approaches (stepwise regression, and genetic programming) are developed for the mixtures tested. The shear modulus and damping ratio of the mixtures are strongly influenced by the percentage of the waste tire crumbs/ buffings inclusions and confining pressure, as expected. Empirical stepwise regression and genetic programming based models for the prediction of shear modulus and damping ratio of the sand -waste tire crumbs/buffings are developed as a function of waste tire types, waste tire content, confining pressure, and shear strain. The genetic programming model is observed to be more accurate than the stepwise regression model. Researchers can use these two models for the prediction of damping ratio and shear modulus of sand - waste tire mixtures. This paper is intended to serve as a leading reference for more advanced applications in geotechnical engineering using both genetic programming and stepwise regression approaches.

\section{References}

[1] Humphrey, D., and Manion, W. "Properties of tire chips for lightweight fill". Grouting, Soil Improvement and Geosynthetics, (Borden, R. H., Holtz, R. O., Juran, I. (Eds.)). (2), pp. 1344-1355. 1992.

[2] Edil, T., and Bosscher, P. "Engineering properties of tire chips and soil mixtures". Geotechnical Testing Journal, 17(4), pp. 453-464. 1994. https://doi.org/10.1520/GTJ10306J

[3] Masad, E., Taha, R., Ho, C., and Papagiannakis, T. "Engineering properties of tire/soil mixtures as a lightweight fill material". Geotechnical Testing Journal, 19(3), pp. 297-304. 1996. https://doi.org/10.1520/ GTJ10355J

[4] Bosscher P. J.,Edil T. B., and Kuraoka S. "Design of highway embankments using tire chips". Journal of Geotechnical and Geoenvironmental Engineering, 123(4), pp. 295-304. 1997. https://doi.org/10.1061/ (ASCE)1090-0241(1997)123:4(295)

[5] Tweedie, J. J., Humphrey, D. N., and Sandford, T. C. "Full scale field trials of tire shreds as lightweight retaining wall backfill at-rest conditions". Transportation Research Records: Journal of the Transportation Research Borard, 1619, pp. 64-71. 1998. https://doi.org/10.3141/1619-08

[6] Humphrey, D. N. "Effectiveness of design guidelines for use of tire derived aggregate as lightweight embankment fill". In: Recycled Materials in Geotechnics Sessions at ASCE Civil Engineering Conference and Exposition 2004, (GSP 127), ASCE, Reston, VA, pp. 61-74. 2004. https:// doi.org/10.1061/40756(149)4

[7] Humphrey, D. N. "Tire derived aggregate as lightweight fill for embankments and retaining walls". In: Proceedings of the International Workshop on Scrap Tire-Derived Geomaterials - Oppurtinities and Challenges (IW-TDGM 2007). Mar. 23-24 2007. Yokosuka, Japan. (Hazarika, H., and Yasuhara, K. (Eds.)). Taylor and Francis, Oxford, UK, pp. 59-81. 2007.

[8] Tanchaisawat, T., Bergado, D. T., Voottipruex, P., and Shehzad, K. "Interaction between geogrid reinforcement and tire chip-sand lightweight backfill". Geotextiles and Geomembranes, 28(1), pp. 119-127. 2010. https://doi.org/10.1016/j.geotexmem.2009.07.002 
[9] Foose, G. J., Benson, C. H., and Bosscher, P. J. "Sand reinforced with shredded waste tires". Journal of Geotechnical Engineering, 122(9), pp. 760-767. 1996. https://doi.org/10.1061/(ASCE)07339410(1996)122:9(760)

[10] Wu, W. Y., Benda, C. C., and Cauley, R. F. "Triaxial determination of shear strength of tire chips". Journal of Geotechnical and Geoenvironmental Engineering, 123(5), pp. 479-482. 1997. https://doi.org/10.1061/ (ASCE)1090-0241(1997)123:5(479)

[11] Feng, Z. Y., and Sutter, K. G. "Dynamic properties of granulated rubber and mixtures". Geotechnical Testing Journal, 23(3), pp. 338-344. 2000. https://doi.org/10.1520/GTJ11055J

[12] Tatlisoz, N., Benson, C. H. and Edil, T. B. "Effect of fines on mechanical properties of soil-tire chip mixtures". ASTM Special Tech Publication, 1275, pp. 93-24. 1997. https://doi.org/10.1520/STP15645S

[13] Yang, S., Lohnes, R. A. and Kjartanson, B. H. "Mechanical properties of shredded tires". Geotechnical Testing Journal, 25(1), pp. 44-52. 2002. https://doi.org/10.1520/GTJ11078J

[14] Zornberg, J. G., Cabral, A. R., and Viratjandr, C. "Behaviour of tire shred - sand mixtures". Canadian Geotechnical Journal, 41(2), pp. 227 241. 2004. https://doi.org/10.1139/t03-086

[15] Pamukcu, S., and Akbulut, S. "Thermoelastic enhancement of damping of sand using synthetic ground rubber". Journal of Geotechnical and Geoenvironmental Engineering, 32(4), pp. 501-510. 2006. https://doi. org/10.1061/(ASCE)1090-0241(2006)132:4(501)

[16] Moo-Young, H., Sellasie, K., Zeroka, D., Sabnis, G. "Physical and chemical properties of recycled tire shreds for use in construction". Journal of Environmental Engineering, 129(10), pp. 921-929. 2003. https://doi. org/10.1061/(ASCE)0733-9372(2003)129:10(921)

[17] Zimmerman, P. S. "Compressibility, hydraulic conductivity, and soil infiltration testing of tire shreds and field testing of a shredded tire horizontal drain". M.S. thesis, Iowa State University. 1997. http://lib. dr.iastate.edu/cgi/viewcontent.cgi?article $=17689 \&$ context $=$ rtd

[18] Attom, M. F. "The use of shredded waste tires to improve the geotechnical engineering properties of sands". Environmental geology, 49(4), pp. 497-503. 2006. 10.1007/s00254-005-0003-5

[19] Venkatappa Rao, G., Dutta, R. K. "Compressibility and strength behaviour of sand-tyre chip mixtures". Geotechnical \& Geological Engineering, 24(3), pp. 711-724. 2006. https://doi.org/10.1007/s10706-004-4006-x

[20] Cabalar, A. F. "Direct Shear Tests on Waste Tires-Sand Mixtures". Geotechnical and Geological Engineering, 29(4), pp. 411-418. 2011. https:// doi.org/10.1007/s10706-010-9386-5

[21] Edincliler, A., Cabalar, A. F., Cevik, A., Cagatay, A. "Triaxial compression behavior of sand and tire wastes using neural networks". Neural Computing and Applications, 21(3), pp. 441-452. 2012. https://doi. org/10.1007/s00521-010-0430-4

[22] Edinçliler, A., Baykal, G., Sayg111, A. "Influence of different processing techniques on the mechanical properties of used tires in embankment construction”. Waste Management, 30(6), pp. 1073-1080. 2010. https:// doi.org/10.1016/j.wasman.2009.09.031

[23] Cabalar A. F. "Applications of the triaxial, resonant column and oedometer tests to the study of micaceous sands". Engineering Geology, 112(1-4), pp. 21-28. 2010. https://doi.org/10.1016/j.enggeo.2010.01.004

[24] Ahmed, I. "Laboratory study on properties on rubber soils". Report No. FHWA/IN/JHRP-93/4, Joint Highway Research Project, Indiana Department of Transportation, USA.1993. http://docs.lib.purdue.edu/cgi/viewcontent.cgi?article $=2547 \&$ context $=$ jtrp

[25] Uchimura, T., Chi, N., Nirmalan, S., Sato, T., Meidani, M., and Towhata, I. "Shaking table tests on effect of tire chips and sand mixture in increasing liquefaction resistance and mitigating uplift of pipe". In: International workshop on scrap tire derived geomaterials-opportunities and challenges. (Hazarika, H., Yasuhara, K. (Eds.)). pp. 179-186. 2008.
[26] Kim, H. K., Santamarina, J. C. "Sand-rubber mixtures (large rubber chips)”. Canadian Geotechnical Journal, 45(10), pp. 1457-1465. 2008. http://www.pmrl.ce.gatech.edu/papers/Kim_2008f.pdf

[27] Hyodo, M., Yamada, S., Orense, R., Okamoto, M., and Hazarika, H. "Undrained cyclic shear properties of tire chip-sand mixtures". In: International workshop on scrap tire derived geomaterials-opportunities and challenges. (Hazarika, H., Yasuhara, K. (Eds.)). pp. 187-196. 2008.

[28] Senetakis, K., Anastasiadis, A. and Pitilakis, K. "Dynamic properties of dry sand/rubber (SRM) and gravel/rubber (GRM) mixtures in a wide range of shearing strain amplitudes". Soil Dynamics and Earthquake Engineering, 33(1), pp. 38-53. 2012. https://doi.org/10.1016/j.soildyn.2011.10.003

[29] Tsang, H. H. "Seismic isolation by rubber--soil mixtures for developing countries". Earthquake engineering \& structural dynamics, 37(2), pp. 283-303. 2008. https://doi.org/10.1002/eqe.756

[30] Tsang, H. H. "Geotechnical Seismic Isolation". In: Earthquake Engineering: New Research. (Miura, T., Ikeda, Y. (Eds.)). Science Publishers, Inc., New York, U.S., pp. 55-87. 2009.

[31] Tsang, H. H., Lam, J. Y. K., Yaghmaei-Sabegh, S., and Lo, S. H. "Protecting Underground Tunnel by Rubber-Soil Mixtures". In: TCLE 2009: Lifeline Earthquake Engineering in a Multihazard Environment, (Alex, K. K., Tang, P. E., Stu Werner, P. E. )Eds.)). Oakland, California, U.S., June 28-July 1. 2009. https://doi.org/10.1061/41050(357)39

[32] Edinçliler, A., Baykal, G., and Dengili, K. "Determination of static and dynamic behavior of recycled materials for highways". Resources, Conservation and Recycling, 42(3), pp. 223-237. 2004. https://doi. org/10.1016/j.resconrec.2004.04.003

[33] Anastasiadis, A., Pitilakis, K., and Senetakis, K. "Dynamic shear modulus and damping ratio curves of sand/rubber mixtures". In: $17^{\text {th }}$ International conference on soil mechanics \& geotechnical engineering. Oct. 2-3. Alexandria, Egypt. 2009.

[34] Anastasiadis, A., Senetakis, K., Pitilakis, K., Gargala, C., Karakasi, I. "Dynamic behavior of sand/rubber mixtures. Part I: Effect of rubber content and duration of confinement on small-strain shear modulus and damping ratio". ASTM Special Technical Publication, 1540, pp. 247. 2012. https://doi.org/10.1520/JAI103680

[35] Senetakis, K., Anastasiadis, A., Pitilakis, K., Souli, A. "Dynamic behavior of sand/rubber mixtures, Part II: Effect of rubber content on G/Goc-DT curves and volumetric threshold strain". ASTM Special Technical Publication, 1540, pp. 248-264. 2012. https://doi.org/10.1520/JAI103711

[36] Cevik, A. "Unified formulation for web crippling strength of cold-formed steel sheeting using stepwise regression". Journal of Constructional Steel Research, 63(10), pp. 1305-1316. 2007. https://doi.org/10.1016/j. jcsr.2007.01.001

[37] Cevik, A., Cabalar A. F. "A genetic programming based formulation for strength enhancement of FRP confined concrete cylinders". Journal of Applied Polymer Science, 110(5), pp. 3087-3095. 2008. https://doi. org/10.1002/app.28839

[38] Cevik, A., Cabalar A. F. "Modelling damping ratio and shear modulus of sand-mica mixtures using genetic programming". Expert Systems with Applications, 36(4), pp. 7749-7757. 2009. https://doi.org/10.1016/j. eswa.2008.09.010

[39] Cabalar, A. F., Cevik, A. "Genetic programming based attenuation relationship of recent earthquakes in Turkey". Computers \& Geosciences, 35(9), pp. 1884-1896. 2009. https://doi.org/10.1016/j.cageo.2008.10.015

[40] Cabalar A. F., Cevik, A. "Triaxial behaviour of sand- mica mixtures using genetic programming". Expert Systems with Applications, 38(8), pp. 10358-10367. 2011. https://doi.org/10.1016/j.eswa.2011.02.051

[41] Chambers, L. D. "The practical handbook of genetic algorithms: Applications.”. Chapman \& Hall/CRC. 2001. 
[42] Rawlings, J. O., Pantula, S. G., Dickey, D. A. "Applied regression analysis: A New Research Tool”. New York: Springer. 1998.

[43] Holland, J. H. "Adaptation in natural and artificial systems: An Introductory Analysis with Applications to Biology, Control and Artificial Intelligence”. MIT Press Cambridge, MA, USA. 1992.

[44] Goldberg, D. E. "Genetic algorithms in search, optimization, and machine learning”. Addison-Wesley Longman Publishing Co., Inc. Boston, MA, USA. 1989.

[45] Haupt, R. L., Haupt, S. E. „Practical genetic algorithms”. Wiley, 2004. ftp://178.213.241.34/pub/Library/BOOKS/heap/SCI\%20BOOKS/ books2/_djvu/Cs_Computer\%20science/CsGn_Genetic,\%20neural/ Haupt\%20R.L.,\%20Haupt\%20S.E.\%20Practical\%20Genetic\%20Algorithms\%20(2ed.,\%20Wiley,\%202004)(ISBN\%200471455652)(261s).pdf
[46] Koza, J. R. "Genetic programming: on the programming of computers by means of natural selection". Cambridge, Mass.: MIT Press. 1992.

[47] Ferreira, C. "Gene expression programming in problem solving". In: Soft Computing and Industry, pp. 635-653. Springer, 2002. https://dx.doi. org/10.1007/978-1-4471-0123-9_54

[48] Ferreira, C. "Gene expression programming: A new adaptive algorithm for solving problems". Complex Systems, 13(2), pp. 87-129. 2001. https://pdfs.semanticscholar.org/3232/b2a24c2584ca8e81cb5bf6f55aef34f0aefe.pdf

[49] Ferreira, C. "Gene expression programming: mathematical modeling by an artificial intelligence". Springer, 2006. 